\title{
Increase of sentinel lymph node melanoma staging in The Netherlands: still room and need for further improvement
}

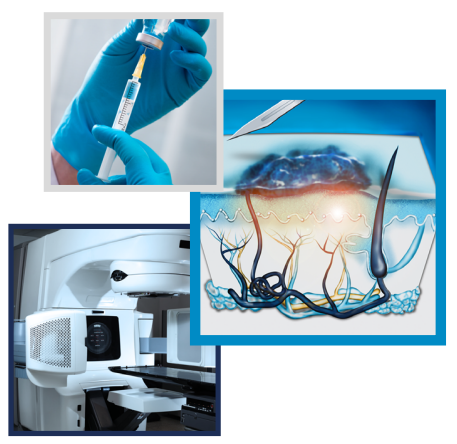

\author{
Harmanjit Singh ${ }^{\ddagger}{ }^{1}$, Anjelli Wignakumar ${ }^{\ddagger}, 1$, Georgina J Williams ${ }^{2}$, Shima Jamshidi ${ }^{3}$, Daniel P \\ Butler $^{2}$, Simon H Wood ${ }^{2}$, Navid Jallali² \& Jonathan A Dunne*,2 \\ ${ }^{1}$ Imperial College School of Medicine, Kensington, London SW7 2DD, UK \\ ${ }^{2}$ Department of Plastic Surgery, Imperial College Healthcare NHS Trust, Charing Cross Hospital, Fulham Palace Rd, Hammersmith, \\ London W6 8RF, UK \\ ${ }^{3}$ Department of Plastic Surgery, Royal Free London NHS Foundation Trust, Pond St, Hampstead, London NW3 2QG, UK \\ *Author for correspondence: jonathan.dunne1@nhs.net \\ $\ddagger$ Joint first authors
}

First draft submitted: 29 July 2020; Accepted for publication: 9 November 2020; Published online: 14 December 2020

Keywords: adjuvant therapy • melanoma • sentinel node

Letter in response to: Deckers EA, Louwman MWJ, Kruijff S, Hoekstra HJ. Increase of sentinel lymph node melanoma staging in The Netherlands; still room and need for further improvement. Melanoma Manag. 7(1), MMT38 (2020).

We read with interest the article by Deckers et al. [1] regarding increased uptake of sentinel lymph node biopsy (SLNB) for melanoma in the Netherlands, which reflects our experience in the UK. Their study encompasses the years 2010-2016 including a large patient cohort, and during this time SLNB was used primarily as a staging tool for melanoma. While differing clinical guidelines were utilized during this period, the 7th edition of the American Joint Committee on Cancer (AJCC) guided who SLNB was primarily offered to, and included tumors which were T1b, constituting a Breslow thickness of $\leq 1 \mathrm{~mm}$ with ulceration or mitoses $\left(\geq 1 / \mathrm{mm}^{2}\right)$ or T2 or greater $(>1 \mathrm{~mm}$ Breslow thickness).

We reviewed all patients presenting with a new diagnosis of cutaneous melanoma to Imperial College Healthcare NHS Trust in London between 1 November 2016 and 31 October 2018. At this time, we offered SLNB for melanomas $\geq 1 \mathrm{~mm}$ Breslow thickness in accordance with guidelines from the National Institute for Health and Clinical Excellence (NICE), which differed marginally to the T1b definition [2]. Patients with regional or distant metastases at presentation were excluded. One hundred and twenty one patients had a new diagnosis of melanoma, of whom 84 (69\%) were eligible for SLNB with a melanoma $\geq 1 \mathrm{~mm}$ Breslow thickness. Thirty nine of the 84 patients (46\%) had SLNB, of whom nine were positive (23\%).

This data identified that our SLNB service may double with increased patient uptake, and could mirror the experience in the Netherlands with an increase year on year. At the end of 2017, adjuvant oncological therapy with Dabrafenib and Tramatenib demonstrated promising results for improved survival following a positive SLNB in BRAF-mutant melanoma [3]. In addition, immunotherapy evolved at a similar time and also demonstrated improved survival [4]. Patient entry for stage III adjuvant therapy trials was primarily those with AJCC 7th edition stage IIIB or C disease, or IIIA with a sentinel lymph node metastatic deposit of $1 \mathrm{~mm}$ or greater. In conjunction with MSLT-2 reporting that completion lymphadenectomy following a positive SLNB did not confer a survival benefit [5], adjuvant oncological therapy became the standard of care, and identifying patients with a positive SLNB has assumed greater importance to improve survival.

Our initial study identified that more than half of patients declined SLNB at a time when adjuvant oncological therapy was not offered. The 8th edition of the AJCC guidelines subsequently lowered the threshold for T1b tumors from 0.8 to $1.0 \mathrm{~mm}$ Breslow thickness without ulceration. In our initial study, that would have made a further 12 patients (10\%) eligible for SLNB if that was used as criteria for offering SLNB. 
In view of lowering the threshold to meet $\mathrm{T} 1 \mathrm{~b}$ tumor criteria, and the availability of life-prolonging treatment for stage 3 disease, we reviewed our SLNB patient uptake between 1 May 2019 and 30 April 2020. At this time, we offered SLNB for T1b tumors and above. Of 72 patients presenting with a new cutaneous melanoma, 40 were eligible for SLNB (55\%), and of these, 35 proceeded (88\%). Six patients (8\%) were in the new T1b category and responsible for a small amount of the increased uptake, while acceptance of SLNB was comparable across AJCC tumor categories. Of four patients with a positive sentinel node, all had a deposit of $1 \mathrm{~mm}$ or greater.

Our service has increased the referrals it receives for cutaneous melanoma over the past 4 years and doubled the numbers of SLNB it is performing. This is reflective of thorough patient counseling to include adjuvant treatment options, which have improved overall survival in melanoma. It has necessitated greater input from nuclear medicine and radiology for SPECT-CT imaging to improve accuracy for head and neck and truncal melanomas, with addition of a further consultant plastic surgeon and increased theater time. The incidence of melanoma is predicted to continue to rise in the UK [6], and SLNB services should anticipate further expansion of services to meet clinical need.

The opinions expressed in this Letter to the Editor are those of the interviewee and do not necessarily reflect the views of Future Medicine Ltd.

\section{Financial \& competing interests disclosure}

The authors have no relevant affiliations or financial involvement with any organization or entity with a financial interest in or financial conflict with the subject matter or materials discussed in the manuscript. This includes employment, consultancies, honoraria, stock ownership or options, expert testimony, grants or patents received or pending, or royalties.

No writing assistance was utilized in the production of this manuscript.

\section{Open access}

This work is licensed under the Attribution-NonCommercial-NoDerivatives 4.0 Unported License. To view a copy of this license, visit http://creativecommons.org/licenses/by-nc-nd/4.0/

\section{References}

1. Deckers EA, Louwman MWJ, Kruijff S, Hoekstra HJ. Increase of sentinel lymph node melanoma staging in The Netherlands; still room and need for further improvement. Melanoma Manag. 7(1), MMT38 (2020).

2. National Institute for Health and Clinical Excellence. Melanoma: assessment and management. (2015). http://www.nice.org.uk/guidance/ng14

3. Long GV, Hauschild A, Santinami M et al. Adjuvant dabrafenib plus trametinib in stage III BRAF-mutated melanoma. N. Engl. J. Med. 377, 1813-1823 (2017).

4. Eggermont AMM, Chiarion-Sileni V, Grob J-J et al. Prolonged survival in stage III melanoma with ipilimumab adjuvant therapy. $N$. Engl. J. Med. 375, 1845-1855 (2016).

5. Faries MB, Thompson JF, Cochran AJ et al. Completion dissection or observation for sentinel-node metastasis in melanoma. $N$. Engl. J. Med. 376, 2211-2222 (2017).

6. Whiteman DC, Green AC, Olsen CM. The growing burden of invasive melanoma: projections of incidence rates and numbers of new cases in six susceptible populations through 2031. J. Invest. Dermatol. 136(6), 1161-1171 (2016). 